\title{
The study of electrical conductivity of spirit solutions of salts
}

\author{
(C) Vera A. Petrukhina, Tatiana A. Kirillova, Ludmila Yu. Tcareva, \\ Ekaterina V. Andreeva, and Nikolay I. Koltsov* ${ }^{+}$ \\ Department of Physical Chemistry and Macromolecular Compounds. I.N. Ulyanov Chuvash \\ State University. Moskovsky Ave., 15. Cheboksary, 428015. Chuvash Republic. Russia. \\ Phone:+7 (8352) 45-24-68. E-mail: koltsovni@mail.ru
}

\begin{abstract}
*Supervising author; ${ }^{+}$Corresponding author
Keywords: spirit solutions of salts, specific and equivalent electrical conductivity, Pisarzhevsky-Valden and Shkodin equations.
\end{abstract}

\begin{abstract}
Electrical conductivity of solutions depends on the nature of the solute and solvent. It is associated with the mobility of ions that are formed during the dissociation of substances in the corresponding solvents. In solvents with large dielectric constant values, substances dissociate into their constituent ions to a greater degree. The dielectric constant of water at room temperature is 78.25. It is a universal solvent and most salts dissolve in it with the decomposition into ions. In proton solvents containing mobile hydrogen ions, salts also dissolve with dissociation into ions. Such solvents include alcohols, the dielectric constant of which is significantly less than the dielectric constant of water. To describe the electrical conductivity of salt solutions in solvents with small dielectric constant, it is proposed to use the Pisarzhevsky-Valden equation in literature. This equation assumes that solvents have a similar chemical nature and the mechanism of salt ion solvation by molecules of different solvents is the same. The degree of solvation changes significantly from one solvent to another for salts containing small ions. This is due to the different solvation of ions in different solvents. Therefore, for such solutions, Pisarzhevsky-Valden equation should not be satisfied. To account for the mechanism of ion solvation in different solvents, A.M. Shkodin proposed an equation that takes into account the dielectric constant of solvent. In this regard the possibility of describing the equivalent conductivity of alcohol solutions of salts with infinite dilution by the equations of Pisarzewski-Valden and Shkodin has been studied in this article.

Electrical conductivity of the studied solutions was judged by the specific $\chi$ and equivalent to $\lambda$ electrical conductivities. These two conductivities are related by the equation $\lambda=\chi / \mathrm{C}$, where $\mathrm{C}$ is the solution concentration. In this article, for salt solutions of with different concentrations in a certain alcohol, the values of $\chi$ and $\lambda$ were found. By analyzing the dependences $1 / \lambda=\mathrm{f}(\lambda \cdot \mathrm{C})$, the values of the limiting equivalent conductivity $\left(\lambda_{\infty}\right)$ were found at $C=0$. For solutions of each salt in different alcohols, the possibility of describing the obtained values of $\lambda_{\infty}$ by the Pisarzhevsky-Valden $\left(\lambda_{\infty} \cdot \eta=\right.$ const $)$ and Shkodin $\left(\lambda_{\infty} \cdot \eta=A \cdot \exp (-B / D)\right.$, where $\eta$ and $\mathrm{D}$ are viscosity and the dielectric constant of alcohol; $\mathrm{A}, \mathrm{B}=$ const). It was found that the experimental data obtained for solutions of sodium iodite and chlorides of cobalt, iron (3), lithium, calcium, nickel, copper, zinc in alcohols (ethanol, propanol-2 and batanol-1) are better described by the Shkodin equation.
\end{abstract}

\section{References}

[1] Vera A. Petruhina, Tatiana A. Kurnaleva, Daria A. Egorova, and Nikolay I. Koltsov Investigation of the influence of temperature on electrical conductivity of aqueous solutions of electrolytes. Part 1. Strong electrolytes. Butlerov Communications. 2016. Vol.45. No.1. P.107-109. DOI: 10.37952/ROI-jbc-01/1645-1-107

[2] V.A. Petruhina, T.A. Kurnaleva, D.A. Egorova, A.S. Vasileva, and N.I. Koltsov. Investigation of the influence of temperature on electrical conductivity of aqueous solutions of electrolytes. Part 2. Weak electrolytes. Butlerov Communications. 2016. Vol.45. No.1. P.110-112. DOI: 10.37952/ROI-jbc-01/1645-1-110

[3] V.A. Petrukhina, E.V. Andreeva, and N.I. Koltsov. Investigation of the influence of temperature on electrical conductivity of aqueous solutions of electrolytes. Part 3. Nitrates. Butlerov Communications. 2017. Vol.49.

No.1. P.104-107. DOI: 10.37952/ROI-jbc-01/17-49-1-104 
[4] V.A. Petrukhina, E.V. Andreeva, and N.I. Koltsov. Investigation of the influence of temperature on electrical conductivity of aqueous solutions of electrolytes. Part 4. Acetates and phosphates. Butlerov Communications. 2018. Vol.53. No.2. P.140-144. DOI: 10.37952/ROI-jbc-01/18-53-2-140

[5] A.V. Izmailov. To the question of relationship between electrical conductivity and viscosity of aqueous solutions of electrolytes. Journal of Physical Chemistry. 1955. Vol.30. No.11. P.2599-2601. (russian)

[6] Yu.Y. Fialkov, A.N. Zhytomyr, Yu.A. Tarasenko. Physical chemistry of non-aqueous solutions. Leningrad: Chemistry. 1973. 376p. (russian)

[7] N.A. Izmailov. Electrochemistry of solutions. Moscow: Chemistry. 1976. 488p. (russian)

[8] The course of physical chemistry, vol. II / Edited by Y.I. Gerasimov. Moscow: Chemistry. 1973. 623p. (russian)

[9] Physical chemistry, book 2. Electrochemistry. Chemical kinetics and catalysis. Edited by K.S. Krasnova. Moscow: High School. 2001. 319p. (russian)

[10] V.V. Eremin, S.I. Kargov, I.A. Uspenskaya, N.E. Kuzmenko, V.V. Lunin. Fundamentals of physical chemistry. Theory and objectives. Moscow: Publishing house "Exam". 2005. 480p. (russian)

[11] A.M. Shkodin. The effect of solvents on the limiting conductivity of ions. Izv. vuzov. Khimiya i khim. tekhnologiya. 1961. Vol.4. No.6. P.941-943. (russian)

[12] A brief guide to physico-chemical quantities. Edited by A.A. Ravdel and A.M. Ponomareva. SanktPeterburg: Publishing house "Ivan Fedorov". 2003. 240p. (russian) 